\title{
Effects of mTOR inhibitor, everolimus, on proliferation, autophagy and temozolomide sensitivity of glioma cells
}

\author{
Wei Dong ${ }^{1}$, Jialiang Wang ${ }^{2 \star}$, Haipeng Liu ${ }^{2}$, Shuo Sun ${ }^{2}$, Yanbin Wang ${ }^{2}$ \\ ${ }^{1}$ Physical Examination Center, ${ }^{2}$ Department of Neurosurgery, Affiliated Hospital of Hebei University, Baoding City, Hebei \\ Province, Baoding, PR China
}

*For correspondence: Email: n6044u@163.com

\begin{abstract}
Purpose: To study the effect of the mTOR inhibitor, everolimus, on glioma cell proliferation, autophagy, and drug sensitivity to temozolomide (TMZ).

Methods: Human glioma cell lines were cultured in vitro, and the effects of different concentrations of everolimus on the proliferation of brain glial cells were determined using CCK-8 method. The effect of different concentrations of everolimus on brain glial cell levels of autophagy protein were assayed by western blot method.

Results: The results of CCK-8 analysis showed that everolimus inhibited the proliferation of glial cells in a time- and concentration-dependent manner. Western blot results showed that the expression levels of autophagy proteins, LC3-II and LC3-IIII, were gradually and concentration-dependently up-regulated, while $p 62$ protein level was gradually decreased concentration-dependently, when compared with blank control $(p<0.05)$. Treatment with different concentrations of TMZ alone, and in combination with everolimus for $48 \mathrm{~h}$ inhibited the proliferation of brain glial cells in a concentration-dependent manner, but the inhibition due to TMZ-everolimus combination was significantly higher than that of TMZ single treatment $(p<0.05)$. After $48 \mathrm{~h}$, the expression level of Beclin-1 increased with the ratio of $L C 3-I / L C-1$ in $T M Z$-everolimus group, while the expression level of p62 decreased, when compared with TMZ alone, or control $(p<0.05)$.

Conclusion: Everolimus significantly inhibits the proliferation of glioma cells and promotes the occurrence of autophagy. Combined use of TMZ and everolimus significantly enhances the sensitivity of $T M Z$ to glioma cells, inhibits cell proliferation, and promotes autophagy better than TMZ alone.
\end{abstract}

Keywords: mTOR inhibitor, Everolimus, Glioma cells, Proliferation, Autophagy

This is an Open Access article that uses a fund-ing model which does not charge readers or their institutions for access and distributed under the terms of the Creative Commons Attribution License (http://creativecommons.org/licenses/by/4.0) and the Budapest Open Access Initiative (http://www.budapestopenaccessinitiative.org/read), which permit unrestricted use, distribution, and reproduction in any medium, provided the original work is properly credited.

Tropical Journal of Pharmaceutical Research is indexed by Science Citation Index (SciSearch), Scopus, International Pharmaceutical Abstract, Chemical Abstracts, Embase, Index Copernicus, EBSCO, African Index Medicus, JournalSeek, Journal Citation Reports/Science Edition, Directory of Open Access Journals (DOAJ), African Journal Online, Bioline International, Open-J-Gate and Pharmacy Abstracts

\section{INTRODUCTION}

Glioma is a high-incidence malignant tumor of the central nervous system due to carcinogenesis in the brain and spinal cord. The incidence of glioma accounts for $1-3 \%$ of all malignant tumors. Most glioma occur in the cerebral hemisphere. Glioma is caused by the interaction between susceptible congenital genetic factors and carcinogenic environmental factors [1]. The symptoms and signs of glioma are related to the location and pathological grade of the tumor. Usually, patients present with headache, nausea, vomiting and blurring, among 
other symptoms. At present, the commonly used clinical treatments are radiotherapy and chemotherapy. However, these treatments are not effective because high-grade gliomas grow rapidly, infiltrate strongly, and easily recur after operation. The median survival time of glioma patients is only 13 months [2].

Autophagy is a cellular protective mechanism which is associated with tumors, degenerative diseases and other human diseases. Autophagy induces programmed cell death through cell membrane degradation and specific gene activation [3]. It is known that mTOR is a serine/threonine protein kinase which regulates the occurrence and development of tumors through P13K/Akt signaling pathway. In addition, the transcription of gene information involved in mTOR signaling pathway regulates autophagy [4].

Everolimus is a specific blocker of the mTOR signaling pathway which is often used to avoid rejection after kidney and heart transplantation. It has been reported that everolimus significantly reduced the proliferation of cancer cell lines in vitro in breast cancer and pancreatic neuroendocrine tumors, and patients treated with TMZ chemotherapy showed good tolerance [5]. Therefore, the purpose of this study was to determine the effects of the mTOR inhibitor everolimus on proliferation, autophagy and TMZ drug sensitivity of glioma cells.

\section{EXPERIMENTAL}

\section{Reagents and instruments}

Glial cell lines were provided by Shanghai Academy of Life Sciences, Chinese Academy of Sciences. Everolimus powder was purchased from Dalian Meilun Biotechnology Co. Ltd, while TMZ powder was purchased from Simga USA. Fetal bovine serum (FBS) was obtained from Hycfone; Cck-8 kit was purchased from Dojindo, Japan, while RPMl1640 medium was purchased from Shanghai Jingke Chemical Technology Co. Ltd. Super clean table was product of Jiabao Purification Engineering Equipment Company. Cell culture kit was purchased from Syme Fisher Technology Co. Ltd, while $-80{ }^{\circ} \mathrm{C}$-refrigerator was bought from Qingdao Haier Co. Ltd. Desk-top high-speed centrifuge was purchased from Simga Warner Precision Instruments. Electron microscope was obtained from Olympus Inc.

\section{Cell culture}

Human brain glial cells were added to RPMI 1640 medium containing $10 \%$ fetal bovine serum, and cultured in an atmosphere of $5 \% \mathrm{CO}_{2}$ at $37{ }^{\circ} \mathrm{C}$ and saturated humidity. The cell culture medium was changed every 2 - 3 days, and cells in good state of logarithmic growth were selected for the experiments.

\section{CCK-8 method}

The CCK-8 method was used to determine the effect of different concentrations of everolimus on brain glial cell proliferation. The brain glioma cells at logarithmic phase were subjected to trypsin digestion, and a broth containing serum preparation was added to the cell suspension in 96-well plates, each well containing about $2 \times 10^{5}$ cells, with $100 \mu \mathrm{L}$ cell suspension per well. The plates were incubated at $5 \% \mathrm{CO}_{2}$ in a constant temperature incubator for $24 \mathrm{~h}$. Then, into the culture plate was put $10 \mu \mathrm{L}$ culture solution containing everolimus at concentrations of 5,10 , 20 and $40 \mu \mathrm{M}$. The blank control group contained only $0.1 \%$ DMSO. Five replicate-wells were set for each group, and the experiment was repeated 3 times. After incubation for 12,24 and $48 \mathrm{~h}$, CCK solution was added for further incubation for $3 \mathrm{~h}$, and the absorbance (OD) value at $450 \mathrm{~nm}$ was determined in a microplate reader. The degree of inhibition of proliferation was calculated as in Eq 1.

$C P I(\%)=\frac{(1-O D E)}{(000)} \times 100$

where $\mathrm{CPI}$ is \% inhibition of cell proliferation, $O D_{e}$ is OD of experimental group, and $O D_{c}$ is $\mathrm{OD}$ of control group.

\section{Western blotting}

Western blotting method was used to determine the effect of different concentrations of everolimus on autophagy protein levels in glial cells. Human glioma cells in logarithmic growth phase were digested with trypsin and placed in a constant temperature incubator at $5 \% \quad \mathrm{CO}_{2}$ incubator overnight, with everolimus working solution added to the culture medium at concentrations of $5,10,20$ and $40 \mu \mathrm{M}$. Thereafter, the cells were washed with PBS solution, and $100 \mu \mathrm{L}$ of cell lysing solution was added to the cell precipitate obtained after centrifugation. The mixture was incubated on ice at $4^{\circ} \mathrm{C}$ for $10 \mathrm{~min}$, followed by centrifugation. The protein content of the supernatant $(10 \mu \mathrm{L})$ was determined using bicinchoninic acid (BCA) test kit. The protein was subjected to SDSpolyacrylamide gel electrophoresis at a voltage of $20 \mathrm{~V}$ for $30 \mathrm{~min}$, and the protein bands were transferred to PVDF membrane. Non-specific binding was blocked by incubating the membrane with non-fat milk solution for $1 \mathrm{~h}$. 
Then, the membrane was incubated overnight at $4^{\circ} \mathrm{C}$ with primary antibodies i.e. rabbit anti-human LC3B, mouse anti-human Beclin-1, and rabbit anti-human P62, each at a dilution of 1:500. Thereafter, the membrane was washed thrice with TBST solution. The hybridized PVDF membrane was placed in a color-developing box for $4 \mathrm{~min}$. Then, the protein bands were scanned and quantified using Odyssey infra-red scanner. The CCK-8 method was also used to determine the inhibitory effect of combination of everolimus and TMZ on human glioma cell proliferation. The TMZ working concentrations were 25, 50, 100 and $200 \mu \mathrm{M}$. The blank control group contained only $0.1 \%$ DMSO. The CCK-8 procedure followed the same steps as described above. Western blotting was also used to determine the effect of everolimus/TMZ combination treatment on human brain glioma cell autophagy protein levels, using the same procedure described above.

\section{Statistical analysis}

Measurement data in this study are expressed as mean \pm SD. Differences among groups were analyzed using analysis of variance (ANOVA), while differences between two groups were analyzed with $t$-test. All statistical analyses were done with SPSS 20.0 software package. Values of $p<0.05$ were considered as statistically significant.

\section{RESULTS}

\section{Effect of everolimus concentration on glial cell proliferation}

CCK-8 method was used to determine the effects of different concentrations of everolimus on the proliferation of glial cells. The results showed that everolimus significantly inhibited the proliferation of glial cells in time- and concentrationdependent manner (Table 1).

\section{Effect of everolimus concentration on autophagy protein levels in glial cells}

Western blot results showed that after treatment of glial cells with different concentrations of everolimus, the expression levels of the autophagy proteins LC3-II, LC3-II /I ratio and Beclin-1 were gradually increased in a concentration-dependent manner, when compared with the blank control group, and the protein level of P62 was gradually decreased in a concentration-dependent manner $(p<0.05$; Table 2, Figure 2).

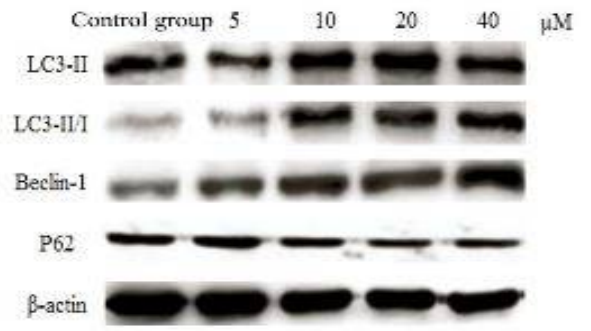

Figure 2: Effect of different concentrations of evimox on autophagy protein levels in glial cells

\section{Effect of TMZ alone, and in combination with everolimus on glial cell proliferation}

The CCK-8 test results showed that treatment of glial cells with different concentrations of TMZ alone or in combination with everolimus for $48 \mathrm{~h}$ inhibited the proliferation of glial cells in a concentration-dependent manner, and the inhibition due to TMZ/ everolimus combination was significantly higher than that of TMZ alone ( $p$ $<0.05$; Figure 3).

Table 1: Inhibitory effect of everolimus on the proliferation of glial cells (\%)

\begin{tabular}{lccccc}
\hline Time (h) & \multirow{2}{*}{ Control group } & \multicolumn{4}{c}{ Concentration of everolimus $(\boldsymbol{\mu M})$} \\
\cline { 3 - 6 } & & $\mathbf{5}$ & $\mathbf{1 0}$ & $\mathbf{2 0}$ & $\mathbf{4 0}$ \\
\hline 12 & $2.78 \pm 1.15$ & $5.21 \pm 1.48^{*}$ & $8.67 \pm 1.55^{\star}$ & $10.54 \pm 1.89^{*}$ & $12.33 \pm 2.10^{*}$ \\
24 & $4.68 \pm 2.11$ & $9.45 \pm 2.22^{*}$ & $12.46 \pm 2.57^{*}$ & $20.88 \pm 2.67^{*}$ & $31.87 \pm 3.12^{*}$ \\
48 & $7.49 \pm 2.25$ & $13.66 \pm 2.31^{*}$ & $21.48 \pm 2.77^{*}$ & $32.65 \pm 2.87^{*}$ & $52.74 \pm 3.28^{*}$ \\
\hline
\end{tabular}

${ }^{\star} P<0.05$, compared with blank control group at the same time

Table 2: Effect of different concentrations of everolimus on autophagy protein levels in glial cells

\begin{tabular}{llllll}
\hline \multirow{2}{*}{ Autophagy protein } & \multirow{2}{*}{ Control group } & \multicolumn{4}{l}{ Concentration of everolimus $(\boldsymbol{\mu M})$} \\
\cline { 3 - 6 } & & $\mathbf{5}$ & $\mathbf{1 0}$ & $\mathbf{2 0}$ & $\mathbf{4 0}$ \\
\hline LC3-II & $0.11 \pm 0.02$ & $0.15 \pm 0.01$ & $0.36 \pm 0.11^{*}$ & $0.42 \pm 0.09^{*}$ & $0.58 \pm 0.12^{*}$ \\
LC3-II/I Ratio & $0.28 \pm 0.05$ & $0.38 \pm 0.06$ & $0.55 \pm 0.07$ & $0.61 \pm 0.11^{*}$ & $0.76 \pm 0.13^{*}$ \\
Beclin-1 & $0.11 \pm 0.03$ & $0.19 \pm 0.02^{*}$ & $0.23 \pm 0.05^{*}$ & $0.48 \pm 0.08^{*}$ & $0.77 \pm 0.17^{\star}$ \\
P62 & $0.59 \pm 0.12$ & $0.52 \pm 0.10$ & $0.38 \pm 0.12^{*}$ & $0.22 \pm 0.04^{*}$ & $0.18 \pm 0.05^{\star}$ \\
\hline
\end{tabular}

${ }^{*} P<0.05$, compared with blank control group 


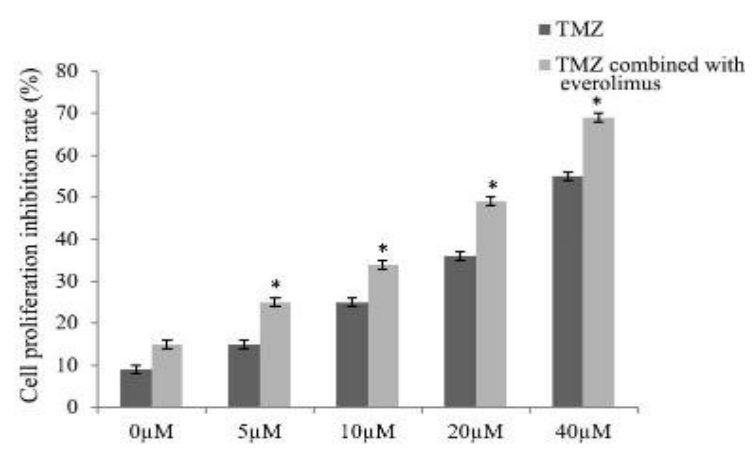

Figure 3: Effect of different concentrations of $T M Z$ alone, and in combination with everolimus on glial cell proliferation. ${ }^{*} p<0.05$, compared with $\mathrm{TMZ}$ alone

\section{Effect of TMZ alone, and in combination with everolimus on autophagy protein levels in glial cells}

Western blot results showed that after treatment of glial cells with TMZ alone or in combination with everolimus for $48 \mathrm{~h}$, LC3-II / ratio and Beclin-1 expression level in TMZ/everolimus combination group showed increasing trends, while P62 expression level showed a decreasing trend, when compared with TMZ alone, and control group (Table 3 and Figure 4).

Table 3: Effect of TMZ alone and in combination with everolimus on autophagy protein levels in glial cells

\begin{tabular}{llll}
\hline $\begin{array}{l}\text { Autophagy } \\
\text { protein }\end{array}$ & $\begin{array}{l}\text { Control } \\
\text { group }\end{array}$ & $\begin{array}{l}\text { TMZ } \\
\text { alone }\end{array}$ & $\begin{array}{l}\text { TMZ } \\
\text { combined } \\
\text { with } \\
\text { everolimus }\end{array}$ \\
\hline LC3-II/I & $0.62 \pm 0.15$ & $1.21 \pm 0.23^{*}$ & $1.93 \pm 0.25^{\star \#}$ \\
Ratio & $0.32 \pm 0.09$ & $0.81 \pm 0.10^{*}$ & $1.68 \pm 0.24^{\star \#}$ \\
Beclin-1 & $1.72 \pm 0.28$ & $1.02 \pm 0.21^{*}$ & $0.62 \pm 0.22^{\star \#}$ \\
P62 &
\end{tabular}

${ }^{\star} P<0.05$, compared with blank control group; $\# p<$ 0.05 , compared with TMZ alone group

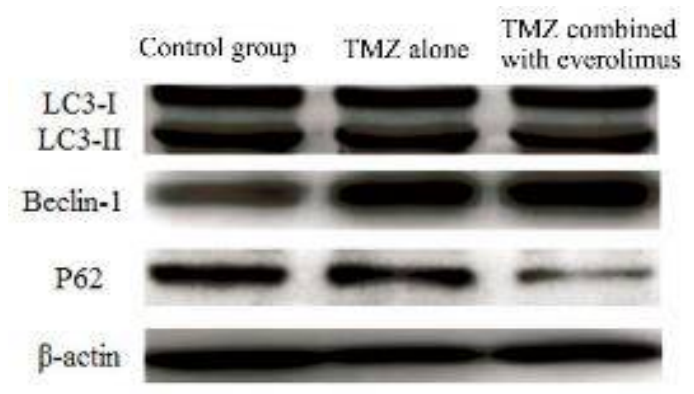

Figure 4: Effect of $\mathrm{TMZ}$ alone, and in combination with evimus on autophagy protein levels in glial cells

\section{DISCUSSION}

Brain glioma is a highly heterogeneous tumor with invasive growth and no obvious boundary with the surrounding brain tissue. The pathogenesis of glioma is not yet clear. However, it is generally believed to be related to genetic, environmental, immune dysfunction and other factors [6]. At present, effective chemotherapy after surgical resection and radiotherapy is still the main method for clinical treatment of brain glioma. However, due to difficulty in achieving complete surgical resection, the patients are prone to recurrence after surgery, with poor prognosis and five-year survival of only $2 \%$ [7]. Therefore, there is need for new treatment methods to improve the survival and prognosis of patients.

mTOR is a downstream effector of mammalian P13K pathway, and it belongs to P13K-related kinases. It regulates tumors through the $\mathrm{P} 13 \mathrm{~K}$ /Akt signaling pathway. The P13k/Akt/mTOR signaling pathway is activated by multiple mechanisms in glioma, and is closely related to cancer [8]. Everolimus is an mTOR inhibitor which induces apoptosis by inhibiting mTOR kinase activation and blocking the regulation of downstream effectors, and by blocking G1-S transformation of cell cycle. Previous studies have demonstrated that everolimus induces autophagy and cell death, and affects the proliferation of glioma cell lines through cytotoxic effects $[9,10]$. Scholars elsewhere have found that everolimus improves the progression-free survival of patients with pancreatic neuroendocrine tumors, and speculated that it may prevent the occurrence of tumors by blocking the $\mathrm{P} 13 \mathrm{k} / \mathrm{Akt} / \mathrm{mTOR}$ pathway [11].

Currently, the US Food and Drug Administration (FDA) has approved everolimus for clinical use in the treatment of renal cell carcinoma and other diseases [12]. Therefore, everolimus plays a significant role in inhibiting tumor proliferation and promoting autophagy. The results of this study showed that treatment of glioma cells with different concentrations of everolimus led to significant inhibition of the proliferation of glial cells, and the inhibitory effect was gradually enhanced with increase in drug concentration and exposure duration.

Autophagy is an effective way to induce excessive self-degradation and death of cells. Previous studies have proved that autophagy is closely related to precancerous lesions and proliferation of tumor cells, and may become a new method of anticancer therapy [13]. The results of this study showed that treatment of glial cells with different concentrations of everolimus led to gradual and concentrationdependent increases in autophagy protein LC3II, LC3-II /LC-I ratio and Beclin-1 expression 
levels, when compared with the blank control group, and the protein level of P62 was gradually decreased in a concentration-dependent manner. These results suggest that everolimus significantly inhibits cell proliferation and promotes autophagy after treatment of glioma cells.

Temozolomide (TMZ) is an oral secondgeneration alkylating agent and imidazoltetrazine derivative which is absorbed quickly after oral administration. It directly crosses the blood-brain barrier, enters the cerebrospinal fluid, and acts on brain tumor tissues. It produces reasonable efficacy and acceptable toxicity, and has obvious efficacy on primary and recurrent malignant glioma [14]. Temozolomide (TMZ) does not exert a direct effect. Rather, it mainly plays a cytotoxic role through DNA guanine methylation, causing autophagic cell death. Relevant data show that TMZ adjuvant chemoradiotherapy significantly improved long-term survival of patients with brain glioma, with obvious synergistic effects [15].

The results of this study show that treatment of glial cells with TMZ alone or in combination with everolimus for $48 \mathrm{~h}$ led to inhibition of the proliferation of glioma cells, with higher inhibition by $\mathrm{TMZ} /$ everolimus combination than $\mathrm{TMZ}$ alone. Compared with $\mathrm{TMZ}$ alone group and control group, LC3-II /LC-I ratio and Beclin-1 expression level in the TMZ/ everolimus group showed upward trends, while P62 expression level showed a downward trend. These results suggest that everolimus enhances the sensitivity of glioma cells to TMZ. Its inhibitory effects on cell proliferation and autophagy are better than that of $\mathrm{TMZ}$ alone, but the specific underlying mechanism needs to be elucidated in further studies.

\section{CONCLUSION}

The results obtained in this study indicate that the mTOR inhibitor everolimus significantly inhibits the proliferation of glioma cells and promotes autophagy. However, combined use of $T M Z$ and everolimus has significantly better enhancing effect on the sensitivity of $T M Z$ to glioma cells, better inhibitory effect on cell proliferation, and better autophagy-enhancing effect than $\mathrm{TMZ}$ alone.

\section{DECLARATIONS}

\section{Conflict of interest}

No conflict of interest is associated with this work.

Contribution of authors
We declare that this work was done by the author(s) named in this article and all liabilities pertaining to claims relating to the content of this article will be borne by the authors, all authors read and approved the manuscript for publication. Jialiang Wang conceived and designed the study, Wei Dong, Jialiang Wang, Haipeng Liu, Shuo Sun, Yanbin Wang collected and analysed the data, while Wei Dong wrote the manuscript.

\section{Open Access}

This is an Open Access article that uses a funding model which does not charge readers or their institutions for access and distributed under the terms of the Creative Commons Attribution License (http://creativecommons.org/licenses/by/ 4.0) and the Budapest Open Access Initiative (http://www.budapestopenaccessinitiative.org/rea d), which permit unrestricted use, distribution, and reproduction in any medium, provided the original work is properly credited.

\section{REFERENCES}

1. Lenting $K$, Verhaak $R$, Laan $M T$, Wesseling $P$, Leenders W. Glioma: experimental models and reality. Acta Neuropathol 2017; 133: 263-282.

2. Buckner JC, Shaw EG, Pugh SL, Chakravarti A, Gilbert $M R$, Barger GR, Coons S, Ricci P, Bullard D, Brown PD, et al. Radiation plus Procarbazine, CCNU, and Vincristine in Low-Grade Glioma. N Engl J Med 2016; 374: 1344-1355.

3. Ho TT, Warr MR, Adelman ER, Lansinger OM, Flach J, Verovskaya EV, Figueroa ME, Passegué E. Autophagy maintains the metabolism and function of young and old stem cells. Nature 2017; 543: 205-210.

4. Mathews ES, Appel B. Cholesterol Biosynthesis Supports Myelin Gene Expression and Axon Ensheathment through Modulation of P13K/Akt/mTor Signaling. J Neurosci 2016; 36: 7628-7639.

5. Nuñez JE, Donadio M, Filho DR, Rego JF, Barros M, Formiga MN, Lopez R, Riechelmann R. The efficacy of everolimus and sunitinib in patients with sporadic or germline mutated metastatic pancreatic neuroendocrine tumors. J Gastrointest Oncol 2019; 10: 645-651.

6. Yang $P$, Qiu Z, Jiang Y, Dong L, Yang W, Gu C, Li G, Zhu $Y$. Silencing of cZNF292 circular RNA suppresses human glioma tube formation via the Wnt/ $\beta$-catenin signaling pathway. Oncotarget 2016; 7: 63449-63455.

7. Ceccarelli M, Barthel FP, Malta TM, Sabedot TS, Salama SR, Murray BA, Morozova O, Newton $Y$, Radenbaugh A, Pagnotta SM, et al. Molecular Profiling Reveals Biologically Discrete Subsets and Pathways of Progression in Diffuse Glioma. Cell 2016; 164: 550-563. 
8. Wu J, Hu G, Dong Y, Ma R, Yu Z, Jiang S, Han Y, Yu K, Zhang $S$. Matrine induces Akt/mTOR signalling inhibition-mediated autophagy and apoptosis in acute myeloid leukaemia cells. J Cell Mol Med 2017; 21: 1171 . 1181.

9. Meng J, Lister J, Vataire AL, Casciano R, Dinet J. Costeffectiveness comparison of cabozantinib with everolimus, axitinib, and nivolumab in the treatment of advanced renal cell carcinoma following the failure of prior therapy in England. Clinicoecon Outcomes Res 2018; 10: 243-250.

10. Gottlieb J, Neurohr C, Müller-Quernheim J, Wirtz H, Sill $B$, Wilkens $H$, Bessa $V$, Knosalla $C$, Porstner $M$, Capusan $C$, et al. $A$ randomized trial of everolimus-based quadruple therapy vs standard triple therapy early after lung transplantation. Am J Transplant 2019; 19: 1759-1769.

11. Franz DN, Lawson JA, Yapici Z, Brandt C, Kohrman MH, Wong M, Milh M, Wiemer-Kruel A, Voi M, Coello N, et al. Everolimus dosing recommendations for tuberous sclerosis complex-associated refractory seizures. Epilepsia 2018; 59: 1188-1197.
12. Mohamed A, Romano D, Saveanu A, Roche $C$, Albertelli $M$, Barbieri F, Brue T, Niccoli P, Delpero JR, Garcia S, et al. Anti-proliferative and anti-secretory effects of everolimus on human pancreatic neuroendocrine tumors primary cultures: is there any benefit from combination with somatostatin analogs? Oncotarget 2017; 8: 4104441063.

13. Liu L, Liao JZ, He XX, Li PY. The role of autophagy in hepatocellular carcinoma: friend or foe. Oncotarget 2017; 8: 57707-57722.

14. Ma MF, Kong LD, Du ZY, Xie ZY, Chen L, Chen RJ, Li $Z Q$, Liu J, Li ZL, Hao AY. A novel stimulus-responsive temozolomide supramolecular vesicle based on hostguest recognition. Colloid Polym Sci 2019; 297: 261 269.

15. Huang J, Chaudhary R, Cohen AL, Fink K, Goldlust S, Boockvar J, Chinnaiyan P, Wan L, Marcus S, Campian JL. A multicenter phase II study of temozolomide plus disulfiram and copper for recurrent temozolomideresistant glioblastoma. J Neurooncol 2019; 142: 537544. 